\title{
REAL-WORLD INFORMATION SYSTEMS PROJECTS IN THE CLASSROOM: FACTORS TO CONSIDER
}

\author{
Michael Taylor, Western Carolina University, mdtaylor4@catamount.wcu.edu \\ Barbara Jo White, Western Carolina University, whiteb@email.wcu.edu
}

\begin{abstract}
Real world projects, many instructors have found, provide students with experiences that prepare them for the real world, enhance their job prospects, and apply what they have learned in the classroom with a real client. This paper describes the ongoing support for information systems projects in the curriculum guidelines, the decision points instructors face when incorporating real world projects in their classes, and uses examples of projects with real clients to illustrate the range of possibilities at each decision point.
\end{abstract}

Keywords: Projects, Teams, Curriculum, Project-Based Learning, Project Management

\section{INTRODUCTION}

The recent IS 2010 Model Curriculum and Guidelines for Undergraduate Programs in Information Systems [26] supports team projects with real clients as a valuable teaching tool with the following benefits for students:

Students should be provided opportunities to work together on team-oriented projects. The group skills developed in this mode are critical to a successful information systems professional (pg. 389).

Team projects with real clients help students apply their classroom learning [26]. In fact, an IS project, as an example of an active learning technique, helps students achieve the highest level of knowledge [7].

However, incorporating real world projects into classroom experiences requires that instructors face a variety of decision points. How will clients be chosen? How should student teams be structured? How many client projects should there be per semester? How much contact do students need with clients and instructors in order to insure a successful project? What types of technologies should projects incorporate?

This paper first addresses how model curriculum guidelines for undergraduate IS programs view the importance of student projects. Second, examples from a variety of information systems projects with real world clients will be used to illustrate the range of possibilities instructors face at various decisions points when incorporating real world projects into their courses. While the vast majority of the published papers on real projects in CIS classrooms are descriptive and not empirical, the purpose of this paper is not to make recommendations about which methods are best, but rather to illustrate the range of possibilities and encourage further research.

\section{REAL WORLD PROJECTS AND THE MODEL CURRICULUM GUIDELINES FOR UNDERGRADUATE IS PROGRAMS}

The most recent curriculum guidelines for undergraduate degree programs in information systems, IS 2010 [26], represents the third collaboration between the Association for Computing Machinery (ACM) and the Association for Information Systems (AIS). Both ACM and AIS had previously worked together with the Association for Information Technology Professionals (AITP), formerly DPMA, to produce a previous version of the model curriculum and guidelines, IS '97 [7], and then IS 2002 [10], considered a relatively minor update to IS '97.

IS 2010 represents a major update from previous versions in that it focuses less on technical issues and more on managerial issues relating to information systems management [26]. Even though there have been major changes in the model curriculum guidelines over the last decade, some aspects have remained constant. One of the aspects of the guidelines that has remained constant has been that all three of the most recent versions of the curriculum 
guidelines $[7,10,26]$ have maintained their focus on IS projects as a means for students to learn skills they need to succeed in the workplace.

IS students need both technical skills and soft skills. Soft skills [26] include the ability to "collaborate with other professionals as well as perform successfully at the individual level...communicate effectively with excellent oral, written, and listening skills (pg. 370)" Concerning technical skills, the guidelines [26] state that students must “...possess skills in understanding and modeling organizational processes and data, defining and implementing technical and process solutions, managing projects, and integrating systems within and across organizations and focus on the application of information technology in helping individuals, groups, and organizations achieve their goals (pg. 370).”

Many of the soft skills and technical skills that IS students need upon graduation can be met while working on projects as easily, if not better, than with lecture. For example, in terms of the specific skills and knowledge that projects can address easily, the recent curriculum guidelines [26] suggest that students need to be proficient at the following: "Ensuring alignment between IT strategy and organizational strategy...; understanding and documenting information requirements...; designing and implementing solutions that provide a high-quality user experience; designing secure systems and data infrastructures; designing and implementing applications...; designing data and information models...; and managing information systems projects (pgs. 378-379).”

These project-related skills can be included in a variety of courses across the undergraduate IS curriculum. The model curriculum guidelines suggest that IS projects are well-suited for courses such as Logical Analysis and Design [7], Physical Design and Implementation [7], IS Security [7], and highly recommended for courses such as IS Project Management [7, 25].

When incorporating real projects with real clients across a variety of IS courses, the guidelines suggest that lab facilities are needed to support this project work. IS 2010 model curriculum guidelines [26] state that appropriate lab facilities are required for "project team laboratories to accommodate team projects essential to the IS program (pg. 365)" a phrase unchanged from the IS1997 [7] and IS2002 [10] guidelines.

Once instructors have decided to incorporate real world projects with real clients into their courses, there are a variety of factors to consider such as the types of projects, project scope and size, team size and composition, the project-client structure, and the amount of contact to build in between students and their clients and instructors.

\section{FACTORS TO CONSIDER WHEN USING REAL WORLD IS PROJECTS IN IS COURSES}

\section{Types of Projects}

Just as technologies emphasized in businesses have changed over the last two decades, so have technologies used in real IS course projects with real world clients. Course projects have utilized a variety of technologies over the last two decades. For example, some of the early projects involved small stand-alone databases [17]. Projects in the late 1990s often involved students working on websites for businesses [16] or school teachers to enable better communication with students and parents [11]. More recently, information systems projects have involved social media, such as Facebook [30]. While there is evidence that students have worked with newer technologies involving mobile web applications [23], there are very few accounts of the experiences of instructors who have incorporated projects involving mobile web applications into their undergraduate IS courses.

\section{Project Scope, Project Size, and Team Size}

Project scope as well as the size of the project and team can be large or small. Scope is often limited due to time constraints or limited resources such as the number of students per class or the number of instructors available [5].

Student teams have worked on projects both large and small. One negative aspect of smaller group projects is that students are not as challenged and exposed to planning activities such as developing requirements, specifications and designs, that are often necessary in larger projects [5]. 
A large scale group project has been defined as any project where the amount of group members is in excess of eight people [8]. Small projects are defined as projects that require group sizes of six or smaller [5]. For teams working on real projects for real clients, team sizes generally range from 2-3 students, [14, 20] to 20-30 students [5, 25].

Larger team sizes typically offer a more realistic experience meaning that communication, management, and other group-work skills are emphasized [8]. Large projects with large groups are also a useful way of exposing students to real world difficulties during group projects [5]. Larger group projects require a greater amount of collaboration and communication between team members [5]. In addition, during large group projects students experience the problems that arise when no one person can fully understand the system [5].

However, large projects are often difficult to implement [5]. Educators often find it difficult to manage a large group of students [5, 27], to find enough time to implement a large project [13], or to assess students on an individual basis [5].

In addition, smaller teams are easier for instructors and students to manage [5]. Therefore, instructors sometimes opt for a small project model where group sizes are smaller and work on smaller projects.

\section{Team Composition}

Several methods have been used to form student teams including the following: student selected teams; instructor selected teams; teams formed with both student and instructor input; and random assignment.

In many cases, groups were selected by students [11 27]. However, students who don't know many of their classmates are often at a disadvantage when groups are student-selected [27]. In addition, conflicts can arise from issues such as scheduling and group chemistry [4].

Instructors have sought to aid in this process by assessing group member strengths, weaknesses, and personality traits prior to selecting groups. Other member characteristics, such as gender have also been used during the group selection process [6]. All-female teams, for example, were beneficial in that there was increased incentive to excel and compete, higher student satisfaction and morale, and greater cooperation [6]. However, when, students are assigned groups with little or no input, it can impact student morale negatively [27].

Only rarely do clients participate in the student team formation process [27]. Additional pressures from clients may also have an added negative effect on group formation. Selection of teams and using only instructor and client input can lead to more conflict compared to student-selected teams [27].

An additional method of forming groups during class projects is a hybrid group formation method in which the teams are formed with input from both instructors and students. Generally students first select their own groups [4, 12]. Then, the instructors assess group members based on capabilities such as programming [4] or details such as course schedule and team member s' ability to meet as a group [12]. The instructors may then reallocate some group members based on information assessed to make sure each team is balanced [4,12]. This allows the students to have input while ensuring that teams are well-rounded which may lead to greater efficiency [4].

In addition to team members being selected by students, instructors, instructors in conjunction with clients, and students in conjunction with instructors, group members may also be selected randomly. Random assignment can simulate a workplace environment in which individuals must work with whoever is on the team when they join [28]. With random assignment, the students must find a way to work together and find out for themselves who they can rely on. One problem arising from this method is that many group members do not know each other, which can hider trust formation [27]. As a result, communication becomes more important using this method because members may be reluctant to communicate at first. 


\section{Project Client Structure: Four Possibilities}

Instructors need to consider the following two factors when choosing projects and clients for the course: how many different projects to involve; and how many clients to involve across the semester. For example, regarding clients, student teams can all work with the same client or each student team can work with its own client. Likewise, regarding projects, student teams can all work on similar projects using similar technologies or each team can work on a project that utilizes a different type of technology. Combining these two factors yields four possibilities for structuring projects and clients (see Figure 1 below).

Figure 1: Four Project-Client Structure Possibilities

\begin{tabular}{|c|c|}
\hline $\begin{array}{l}\text { Different Client } \\
\text { Same Project }\end{array}$ & $\begin{array}{l}\text { Different Client } \\
\text { Different Project }\end{array}$ \\
\hline Same Client & Same Client \\
\hline Same Project & Different Project \\
\hline
\end{tabular}

Project

Same Client-Same Project: When student teams essentially work on the same project for the same clients, it introduces the element of competition [12,13]. The idea is that this simulates a typical market in which competing firms bid on the same clients. In addition, competition stimulates learning. When students compete on the same projects, they often learn different approaches to the same problem from different student teams [12]. Often, competition introduces peer pressure, which often leads to higher quality projects [12]. One disadvantage of this method is that the potential for cheating is elevated [12], which makes assessment more difficult [2]. How much collaboration is allowed before it is classified as plagiarism?

Same Client-Different Projects: Others argue that working cooperatively on different aspects for one client is better because it more closely resembles working within an organization, in which all employees must cooperate to achieve a similar goal [2,5]. This type of structure, in which student teams all work on a project for one client, can occur when student teams each work on different modules of a large system. For example, one IS project required that student teams work on different features for a social networking site, for one client who worked with each of the student teams individually [30].

Different Client, Same Project: This category is well-illustrated by projects such as students and student teams that built websites for elementary school teachers [11] in which each elementary teacher served as a different client. Student evaluations of this particular project focused less on technology and more on client differences. Although, student awareness of the importance of soft skills rose by the end of the project, many students had negative reactions to their clients. For example, student ratings regarding perception of the elementary school teacher clients as well as their project enjoyment was lower at the end of the project compared to the beginning of the project [11]. However, one advantage for the instructor that occurs when all students are using similar technologies, such as web site development, is that it may facilitate grading.

Different Client-Different Projects: Alternatively, instructors may also want student teams to each work on a separate project for a separate client. This exposes students to different team-client relationships and a wider variety of projects [19]. This allows students to learn not only a great deal about their clients, but also a small amount about other groups' projects. [12]. One drawback to this method is that it is often difficult for instructors to find enough viable clients for students [13]. 
Volume XII, No. 2, pp 135-141, 2011

\section{Amount of Student Team Contact With Clients \& Instructors}

Contact between student teams and instructors is essential to make sure the projects are on schedule [13]. Generally, student teams may meet with instructors as few as three to four times a semester [12] up to as many as six to eight times a semester with meetings lasting approximately an hour [30]. Student learning is not necessarily adversely affected by having fewer meetings. While, some are in favor of increased instructor involvement [13], others believe students may also learn through project failure that can be partially due to less instructor involvement [24].

In addition to student teams maintaining contact with instructors, they also need to maintain contact with their clients. Current wisdom regarding activities with end users of information systems suggests that activities such as keeping users involved and managing stakeholder expectations results in higher levels of end user satisfaction [3, 9, 15, 21]. However, maintaining contact with the client does not have to require extensive, frequent meetings. Real world IS projects in IS courses have been successful regardless of whether students met with clients less regularly, such as two to four times a semester [14], or more regularly, such as weekly [29].

However, one reason why students and clients don't meet more regularly has to do with scheduling problems. For example, student team members can go to a meeting and client representatives do not show up due to work constraints, or students are unavailable to meet during typical business hours due to class schedules [1]. This may leave clients wishing for more contact with students at the end of the project [19], and can result in the university's reputation suffering [18].

To avoid differing expectations among clients and students, instructors can consult with student teams and clients about expectations of involvement prior to the student teams committing to the project [22]. Another way to make sure student teams and clients have similar expectations regarding the frequency of meetings is to codify expectations in a memorandum of understanding.

\section{SUMMARY}

If instructors are interested in including real information systems projects with real clients, they must make a variety of decisions from project size to how many projects and how many clients to include in a semester to how to structure teams in terms of size and composition.

Model curriculum guidelines for IS programs for undergraduate students [7, 10, 26] all support the use of information systems projects to facilitate student learning. Whether projects are simulated or are for real clients, student teams have the opportunity to learn the necessary technical skills.

However, when student teams work on real projects for real clients, they also have the opportunity to learn the necessary soft skills for a successful career. These soft skills include the ability to interact with clients by listening, interviewing, and reviewing requirements with them. In addition, student team members have the opportunity to analyze this communication, along with other system requirement documentation, and use it to drive the system design, which clients can give feedback on at regular intervals.

\section{FUTURE DIRECTIONS}

The area of incorporating real projects in CIS classrooms is ripe for future research. First, the vast majority of previous papers included in this study are descriptive and not empirical. Second, the previous papers did not fully address all factors that instructors need to consider when planning to include real projects in their classes. For example, few papers included in this study made mention of the issue of social loafing, or poor student performance in teams [4, 5, 22]. In addition, although one paper [5] described in detail the difficulties dealing with individual evaluation in group projects, others $[1,4,17]$ provide only a paragraph on evaluation, while others $[6,11,24,28]$ only lightly mention the topic of evaluation and grading. Thus, work in the areas of social loafing and evaluation and grading as well as empirical work in the area of real CIS projects in CIS classrooms is necessary and welcome. 
Volume XII, No. 2, pp 135-141, 2011

\section{REFERENCES}

1. Ali, A., DeLorenzo, G., Mensch, S., \& Kohun, F. (2008). Integrating service learning projects into technology courses: The experience of two programs. Issues in Information Systems, 9 (1), 121-128.

2. Bullers, Jr., W. I. (2003). Optional projects in the database course: Implications for student performance. Issues in Information Systems, 4, 383-389.

3. Cavaye, A. (1995). User participation in system development revisited. Information and Management, 28, 311323.

4. Chen, B. (2006). Teaching systems analysis and design: Bringing the real world into the classroom. Information Systems Education Journal, 8 (4), 1-8.

5. Coppit, D. (2006). Implementing large projects in software engineering courses. Computer Science Education, 16 (1), 53-73

6. Cox, A., \& Fisher, M. (2008). A qualitative investigation of an all-female group in a software engineering course project. Journal of Information Technology Education, 7, 1-20.

7. Davis, G. B., Gorgone, J. T., Couger, J. D., Feinstein, D. L., \& Longenecker, Jr., H. E. (1997). "IS ‘97 Model Curriculum and Guidelines for Undergraduate Degree Programs in Information Systems,” ACM, New York, NY and AITP [formerly DPMA), Park Ridge, IL.

8. Gillies, A., \& Gillies, L. (1999). A large-scale software engineering group project at the University of the West of England, Bristol. Computer Science Education, 9(3). 268-280.

9. Ginzberg, M. (1981). Key recurrent issues in the MIS implementation process. MIS Quarterly, 5, 47-59.

10. Gorgone, J. T., Davis, G. B., Valacich, J. S., Topi, H., Feinstein, D. L., \& Longenecker, Jr., H. E. (2002). “IS 2002 Model Curriculum and Guidelines for Undergraduate Degree Programs in Information Systems,” ACM, New York, NY and AITP (formerly DPMA), Park Ridge, IL.

11. Guthrie, R., \& Navarrette, C. (2004). Service-learning impact on IS students in a web development course. Information Systems Education Journal, 2(12), 1-12.

12. Harris, R. (2009). A systems analysis and design semester project: A stand-alone project vs a competitive project. Information Systems Education Journal. 7 (11), 1-9.

13. Helwig, J. (2006). Using a "real” systems development project to enrich a systems analysis and design course. Information Systems Education Journal, 4(62), 1-8.

14. Janicki, T. (April, 11, 2011). Email interview.

15. Lakhanpal, B. (1993). Understanding the factors influencing the performance of software development groups: an exploratory group-level analysis. Information \& Software Technology, 35, 468-473.

16. Lazar, J. (2000). Teaching web design through community service projects. Journal of Informatics Education and Research, 2(2) 71-75.

17. McDonald, G., \& McDonald, M. (1992). The effectiveness of peer reviews and process logs in team projects. Journal of Information Systems Education, 3(2), 21-26.

18. Parker, H., Holcombe, M., \& Bell, A. [1999). Keeping our customers happy: Myths and management issues in "client-led" student software projects. Computer Science Education, 9(3), 230-241.

19. Pratt, J. A. (2002). Designing, developing, teaching an e-commerce web design class. Issues in Information Systems, 3, 522-528.

20. Reinicke, B. (April 8, 2011) Email Interview.

21. Sawyer, S., Guinan, P.J., \& Cooprider, J. (2010). Social interactions of information systems development teams: A performance perspective. Information Systems Journal, 20, 81-107.

22. Scott, E. (2006). Systems development group project: A real-world experience. Information Systems Education Journal, 4 (23), 1-10.

23. Scott, E. (May 7, 2011). Email Interview.

24. Tompsett, B. (1989). The system cottage- a multidisciplinary engineering group practical. Software Engineering Journal, 4 (4), 209-220

25. Tvedt, J., Tesoriero, R., \& Gary, K. A. (2002). The software factory: An undergraduate computer science curriculum. Computer Science Education. 12(1), 91-117.

26. Topi, H., Valacich, J. S., Wright, R. T., Kaiser, K., Nunamaker, Jr., J. F., Sipior, J. C., \& de Vreede, G. J. (2009). IS 2010: Curriculum Guidelines for Undergraduate Degree Programs in Information Systems. Communications of the Association for Information Systems, 26, 359-428. 


\section{Volume XII, No. 2, pp 135-141, 2011}

27. Vartiainen, T. (2005). Moral Conflicts in a Project Course in Information Systems Education. Jyväskylä: Department of Computer Science and Information Systems, University of Jyväskylä.

28. Vaughan, Jr., R. B. (2001). Teaching industrial practices in an undergraduate software engineering course. Computer Science Education, 11[1), 21-32.

29. Yue, K. B. [April 8, 2011). Email Interview.

30. Yue, K. B., De Silva, D., Kim, D., Aktepe, M., Nagle, S., Boerger, C., Jain, A., \& Verma, S. (2009). Building real world domain-specific social networking websites as a capstone project. Journal of Information Systems Education, 20[1), 67-76. 